\title{
Study of the relationship between anxiety and obesity by means of the State-Trait Anxiety Inventory (STAI) questionnaire
}

\author{
Manuel Antonio Rubio Sánchez \\ CIME Clinic, Badalona, Spain
}

Email address:

mrubio@clinica-cime.com

To cite this article:

Manuel Antonio Rubio Sánchez. Study of the Relationship between Anxiety and Obesity by Means of the State-Trait Anxiety Inventory (STAI) Questionnaire. Journal of Surgery. Special Issue: Breakthroughs in Aesthetic Medicine. Vol. 3, No. 1-1, 2015, pp. 14-17. doi: $10.11648 /$ j.js.s.2015030101.15

\begin{abstract}
The usual relationship between excessive food intake and anxiety described by most obese patients takes us directly to these people's reality. Something described as external to them, uncontrolled and erratic is "what makes them behave like that". Changing this perception of the problem of excessive intake, redirecting it to the patient and giving them a sense of self-control is by no means easy. The purpose of this study was to determine to what extent obesity is truly a problem of anxiety and whether it is actually a matter of bad eating habits. Thirty subjects were evaluated and asked to answer the STAI questionnaire in order to assess their state anxiety and trait anxiety.
\end{abstract}

Keywords: Obesity, Anxiety, STAI Questionnaire

\section{Introduction}

During doctor visits due to obesity, patients claim to overeat due to anxiety. Obesity is currently considered a public health issue worldwide. Between $15 \%$ and $20 \%$ of the adult population in Europe is obese, and $64 \%$ of the adult population in the United States is estimated to be overweight or obese $[1,2]$.

Obesity can be defined as an imbalance between caloric intake and caloric expenditure resulting in an abnormal or excessive accumulation of body fat. The development of this state involves various factors of heterogeneous origins which lead to an obese phenotype [3]. The massive literature on the subject covers several aspects including prevention, physiopathology, and treatment [4]. However, the same attention has not been given to the psychological component, although the presence of a psychological disorder may have influence on the development of obesity and affect treatment discontinuation.

States of anxiety can vary in intensity and change over time. However, when anxiety is present as an individual, relatively stable difference, it is considered a personality trait. The difference between state anxiety (SA) and trait anxiety (TA) is that SA refers to how a person feels at a given time (the environmental factors which protect or create anxiety), while
TA refers to how a person feels usually (a personality factor causing a predisposition to anxiety or not) [3].

The relevance of this pathology; its social, cultural, psychological and health repercussions; and the recurrent claim by patients that anxiety is the main cause of their obesity warrant this study whose purpose has been to determine the state anxiety or trait anxiety levels at the start of obesity treatment.

\section{Material and Methods}

The study population included 30 obese patients $(83.3 \%$ women and $16.7 \%$ men) recruited consecutively between October 2011 and June 2012. The provisions of the Declaration of Helsinki regarding ethical principles for medical research involving human subjects have been respected. The inclusion criteria were: correctly completing the STAI questionnaire at the first visit, Body Mass Index (BMI) between $29.9 \mathrm{~kg} / \mathrm{m}^{2}$ and $39.9 \mathrm{~kg} / \mathrm{m}^{2}$, age between 18 and 65 , exogenous or simple obesity, no eating disorders, no diagnosis of psychiatric pathology, and no concomitant drug treatment. 
The weight and height of subjects were recorded (Seca scales and height measuring equipment, Vogel and Halke, model 701, Hamburg). Measurements were taken with the subjects barefoot and in their underwear. The STAI test was used to assess state-trait anxiety (table 1, table 2, figure 1). The STAI is a self-referential 40-item questionnaire which measures two types of anxiety: SA and TA. It is a reliable and valid instrument which has been standardized for this population. The STAI items have good internal consistency between 0.84 and 0.93 , and a test-retest reliability between 0.86 and 0.96 . Patients completed the questionnaire during the evaluation period and at the start of treatment. The Spanish adaptation of this test by Bermúdez (1983) [5] was used.

The assumption of normality was tested with the Shapiro-Wilk test, and the assumption of homoscedasticity was tested with Fisher's F test. Means were used as an index of central tendency and standard deviation was used as index of dispersion. Statistical analysis was performed with SPSS (9.0) software. In all cases, the level of statistical significance was set at $\mathrm{p}<0.05[4]$.

\section{Results}

Assumptions of normality $(p<0.05)$ and assumptions of homoscedasticity $(p<0.05)$ were accepted. Mean weight was $86.91 \mathrm{~kg}$ (SD: 8.73 ), mean height was $161.8 \mathrm{~cm}$ (SD: 1.32 ), and mean BMI was $34.4 \mathrm{~kg} / \mathrm{cm}^{2}$ (SD: 3.11 ). Mean age was 40.87 years (SD: 13.46). Mean STAI-S score: 25.83 (SD: 14.73). Mean STAI-T score: 27.83 (SD: 13.77).
In this study group of 30 patients no significant differences between state and trait anxiety were found. Breakpoints for both characteristics are marked anxiety, in order to observe the variability of the data in relation to both types of anxiety. (STAI-S: 31; STAI-T: 32).

\section{Discussion}

Regarding state and trait anxiety, the study by Calderón et al, 2009 [6] stresses that it is trait anxiety which substantially increases the risk of perpetuating obesity in patients, while state anxiety does not reach predictive value in explaining the BMI of obese patients [6]. N. Schmitz [4] states that the definition of anxiety should take into account that symptoms usually develop when an individual is exposed to specific stress factors, while anxiety is classified as a clinical disorder when symptoms are bad enough to interfere with performance. The anxiety disorder is contextual in nature. Obese persons could structure their lives so as to avoid situations causing anxiety, and therefore their lives may differ significantly from the lives chosen by normal weight individuals [4]; this is related to the results of the STAI questionnaire obtained in this study, which showed insignificant values. G. Gariepy [4] suggests that obesity and anxiety disorder in obese patients are partly hereditary and may share a common genetic base. However, this has not been proven in this study, as less than half of patients exhibited a first-grade family history of obesity.

Table 1. STAI Questionnaire (part 1)

\begin{tabular}{|c|c|c|c|c|}
\hline Statement & Not at all & Somewhat & Moderately so & Very much so \\
\hline 1. I feel calm & 1 & 2 & 3 & 4 \\
\hline 2. I feel secure & 1 & 2 & 3 & 4 \\
\hline 3. I am tense & 1 & 2 & 3 & 4 \\
\hline 4. I feel strained & 1 & 2 & 3 & 4 \\
\hline 5. I feel at ease & 1 & 2 & 3 & 4 \\
\hline 6. I feel upset & 1 & 2 & 3 & 4 \\
\hline 7. I am presently worrying over possible misfortunes & 1 & 2 & 3 & 4 \\
\hline 8. I feel satisfied & 1 & 2 & 3 & 4 \\
\hline 9. I feel frightened & 1 & 2 & 3 & 4 \\
\hline 10. I feel comfortable & 1 & 2 & 3 & 4 \\
\hline 11. I feel self-confident & 1 & 2 & 3 & 4 \\
\hline 12. I feel nervous & 1 & 2 & 3 & 4 \\
\hline 13. I am jittery & 1 & 2 & 3 & 4 \\
\hline 14. I feel indecisive & 1 & 2 & 3 & 4 \\
\hline 15. I am relaxed & 1 & 2 & 3 & 4 \\
\hline 16. I feel content & 1 & 2 & 3 & 4 \\
\hline 17. I feel worried & 1 & 2 & 3 & 4 \\
\hline 18. I feel confused & 1 & 2 & 3 & 4 \\
\hline 19. I feel steady & 1 & 2 & 3 & 4 \\
\hline 20. I feel pleasant & 1 & 2 & 3 & 4 \\
\hline
\end{tabular}

Directions given to voluntaries: "A number of statements which people have used to describe themselves are given below. Read each statement and then circle the appropriate number to the right of the statement to indicate how you feel right now, that is, at this moment. There are no right or wrong answers. Do not spend too much time on any one statement but give the answer which seems to describe your present feelings best". 
Table 2. STAI Questionnaire (part 2)

\begin{tabular}{|c|c|c|c|c|}
\hline Statement & Almost never & Sometimes & Often & Almost always \\
\hline 1. I feel pleasant & 1 & 2 & 3 & 4 \\
\hline 2. I feel nervous and restless & 1 & 2 & 3 & 4 \\
\hline 3. I feel satisfied with myself & 1 & 2 & 3 & 4 \\
\hline 4. I wish I could be as happy as others seem to be & 1 & 2 & 3 & 4 \\
\hline 5. I feel like a failure & 1 & 2 & 3 & 4 \\
\hline 6. I feel rested & 1 & 2 & 3 & 4 \\
\hline 7. I am "calm, cool, and collected" & 1 & 2 & 3 & 4 \\
\hline 8. I feel that difficulties are piling up so that I cannot overcome them & 1 & 2 & 3 & 4 \\
\hline 9. I worry too much over something that really doesn't matter & 1 & 2 & 3 & 4 \\
\hline 10. I am happy & 1 & 2 & 3 & 4 \\
\hline 11. Have disturbing thoughts & 1 & 2 & 3 & 4 \\
\hline 12. I lack self-conficence & 1 & 2 & 3 & 4 \\
\hline 13. I feel secure & 1 & 2 & 3 & 4 \\
\hline 14. I make decisions easily & 1 & 2 & 3 & 4 \\
\hline 15. I feel inadequate & 1 & 2 & 3 & 4 \\
\hline 16. I feel content & 1 & 2 & 3 & 4 \\
\hline 17. Some unimportant thought runs through my mind and bothers me & 1 & 2 & 3 & 4 \\
\hline 18. I take disappointments so keenly that I can't put them out on my mind & 1 & 2 & 3 & 4 \\
\hline 19. I am a steady person & 1 & 2 & 3 & 4 \\
\hline $\begin{array}{l}\text { 20. I get in a state of tension or turmoil as I think over my recent concerns and } \\
\text { interest }\end{array}$ & 1 & 2 & 3 & 4 \\
\hline
\end{tabular}

Directions given to voluntaries: "A number of statements which people have used to describe themselves are given below. Read each statement and then circle the appropriate number to the right of the statement to indicate how you generally feel. There are no right or wrong answers. Do not spend too much time on any one statement but give the answer which seems to describe your present feelings best".

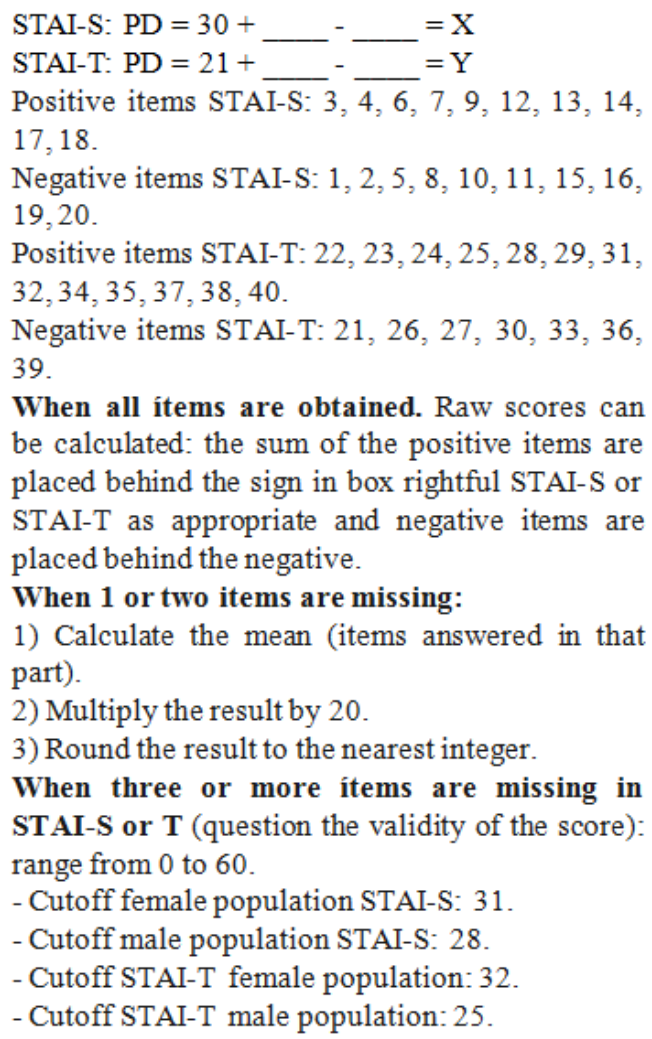

STAI-S: PD $=30+$ $=\mathrm{X}$

STAI-T: PD $=21+$ $=\mathrm{Y}$

Positive items STAI-S: $3, \overline{4,6}, 7,9,12,13,14$, 17,18 .

Negative items STAI-S: $1,2,5,8,10,11,15,16$, 19,20 .

Positive items STAI-T: $22,23,24,25,28,29,31$, $32,34,35,37,38,40$

Negative items STAI-T: $21,26,27,30,33,36$, 39.

When all ítems are obtained. Raw scores can be calculated: the sum of the positive items are placed behind the sign in box rightful STAI-S or STAI-T as appropriate and negative items are placed behind the negative.

When 1 or two items are missing:

1) Calculate the mean (items answered in that part).

2) Multiply the result by 20 .

3) Round the result to the nearest integer.

When three or more ítems are missing in

STAI-S or T (question the validity of the score): range from 0 to 60 .

- Cutoff female population STAI-S: 31

- Cutoff male population STAI-S: 28.

- Cutoff STAI-T female population: 32

- Cutoff STAI-T male population: 25

Figure 1. State Trait Anxiety Inventory for Adults Scoring Key

Regarding the main objective of this study, namely to assess obese patients at the start of treatment in order to determine their levels of state and trait anxiety, we have concluded that these patients do not exhibit any significant indices suggesting a situation of anxiety; on the contrary, an examination of their diet and psychonutritional profiles revealed bad eating habits such as overabundant meals, eating too quickly, snacking between meals, and not eating the five meals recommended per day. Future studies should be carried out to confirm this claim. In addition, a detailed study including gender-specific analysis is desirable considering the significant differences in STAI-T/S between men and women (mean STAI-S score in men: 19.2; mean STAI-S score in women: 27.2; mean STAI-T score in men: 24.4; mean STAI-T score in women: 28.5).

The results of this study allow us to analyze and recognize that eating habits and an increasingly sedentary lifestyle are some of the main factors lie behind what is now known as the epidemic of obesity and affects approximately $16 \%$ of the Spanish population. Health professionals must take action on this, not only giving nutritional guidelines related to diet, we have to make a food reeducation our patients, this is the best way to fight obesity.

\section{References}

[1] Bjorntorp P. Obesity. Lancet 1997;350(9075):423-6.

[2] Flegal KM, et al. Prevalence and trends in obesity among US adults. JAMA 1999; 288(14):1723-7.

[3] Jadue L, et al. Factores de riesgo para enfermedades no transmisibles: metodología y resultados globales de la encuesta base del programa CARMEN. Rev Med Chile 1999;127; 1004-13.

[4] G Gariepy, D Nitka and N Schmitz, et al. La asociación entre el tratamiento de la obesidad y la ansiedad. Department of Epidemiology, Biostatistics and Occupational Health, McGill University, Montreal, Quebec, Canadá. International Journal of Obesity 2010;34:407-19. 
[5] C. D. Spielberger, R. L. Gorsuch \& R. E. Lushene. STAI Cuestionario de Ansiedad Estado-Rasgo Manual. 2008. Madrid: TEA ediciones.

[6] C. Calderón, M.a Forns y V. Varea, et al. Implicación de la ansiedad y la depresión en los trastornos de alimentación de jóvenes con obesidad. An Pediatr 2009;71(6):489-94.

[7] Nammi S, et al. (2004). Obesity: An overview on its current perspectives and treatment options. Nutr J. 3(1), 3 .
[8] Kain J, et al. (2001). Validación y aplicación de instrumentos para evaluar intervenciones educativas en obesidad de escolares. Revista Chilena de Pediatría. 72(4), 308-318.

[9] Quetelet LAJ. (1871). Antropométrie ou Mesure des Différences Facultés de l'Homme. Brussels: Musquardt.

[10] Buitrago F, Ciurana R, Chocron L, et al.(1999). Prevención de los trastornos de la salud mental desde la atención primaria de salud. Rev. Med. Chile. 24 (1), 184-190. 